\title{
Effects of Phosphate Bioglass on Sintering of Hydroxyapatite Scaffolds by Freeze-Drying
}

\author{
Luwei $\mathrm{Fu}^{1}$, Jin Wen ${ }^{1,2, a}$, Hongquan Zhang ${ }^{1,2, b}$, Ying Guo ${ }^{1}$, Fei Yang ${ }^{1}$ \\ ${ }^{1}$ State Key Laboratory of Silicate Materials for Architecture (Wuhan University of Technology), \\ Wuhan 430070, China \\ ${ }^{2}$ School of Materials Science and Engineering, Wuhan University of Technology, \\ Wuhan 430070, China

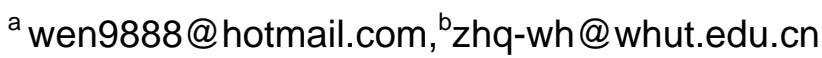

Keywords: Phosphate bioglass; Hydroxyapatite scaffolds; Sintering

\begin{abstract}
Effects of phosphate bioglass on sintering of hydroxyapatite $\left(\mathrm{Ca}_{10}\left(\mathrm{PO}_{4}\right)_{6}(\mathrm{OH})_{2}, \mathrm{HA}\right)$ scaffolds prepared by freeze-drying casting was studied. The phosphate bioglass, acted as a binder, was added in a mixture of HA powders and forming additives. The result shows that the phosphate bioglass binder could improve the sintering behavior and reduce the sintering temperature, but it could promote the transformation of $\mathrm{HA}$ into $\beta-\mathrm{Ca}_{3}\left(\mathrm{PO}_{4}\right)_{2}$ and $\mathrm{Ca}_{2} \mathrm{P}_{2} \mathrm{O}_{7}$.
\end{abstract}

\section{Introduction}

Bioglass has been successfully used as implants for bone augmentation and restoration of hard tissues in the form of dense, implants, scaffolds and coating[1, 2]. Nevertheless, bioglass-made substitutes containing high content of silicate have been claimed to show a toxicity in the previous studies [3]. Thus, bioglass materials with low or no silicate have attracted more attention. Although such phosphate bioglass shows good bioactivity and biocompatibility as well as low sintering temperature, high biological solubility and biodegradability greatly impair its further biomedical application [4, 5].

Synthetic hydroxyapatite $\left(\mathrm{Ca}_{10}\left(\mathrm{PO}_{4}\right)_{6}(\mathrm{OH})_{2}, \mathrm{HA}\right)$ is an active biomaterials for hard tissues implants of humans, and HA-based materials have been widely applied in the medical fields in the form of granules, blocks, and dense bodies[6]. Unfortunately, most of synthetic HA scaffolds prepared at high sintering temperature about $1300^{\circ} \mathrm{C}$ have high elastic modulus, low mechanical strength and reduced bioactivity [7-9].It has been found that bioglass could be used as a binder to reduce the sintering temperature of pure HA ceramics, and the sintering shrinkage rate for both dense and foam HA increases with increasing content of the bioglass [10,11]. What's more, the bioglass would promote $\mathrm{HA}$ to decompose into $\beta-\mathrm{Ca}_{3}\left(\mathrm{PO}_{4}\right)_{2}$ and $\mathrm{Ca}_{2} \mathrm{P}_{2} \mathrm{O}_{7}$. However, no more literatures were found about the effect of phosphate bioglass on sintering of HA scaffolds. The aim of this research is to prepare the HA scaffolds at low temperature and study the effects of phosphate bioglass on sintering, morphology and phases of HA scaffolds as well as appropriate content of phosphate bioglass in HA scaffolds.

\section{Materials and Methods}

Preparation of $\mathrm{HA}$ and phosphate bioglass. HA powders were prepared by homogeneous precipitation using $\mathrm{Ca}\left(\mathrm{NO}_{3}\right)_{2} \cdot 4 \mathrm{H}_{2} \mathrm{O}, \mathrm{NH}_{4} \mathrm{H}_{2} \mathrm{PO}_{4}, \mathrm{NH}_{4} \mathrm{OH}$ (AR, Sinopharm Chemical Reagent Co., Ltd. China). $0.3 \mathrm{~mol} / \mathrm{L}$ phosphate solution was slowly added dropwise to $0.5 \mathrm{~mol} / \mathrm{L}$ calcium solution at $5 \sim 10 \mathrm{~mL} / \mathrm{min}$ under constant stirring with a magnetic bar at room temperature. The solution $\mathrm{pH}$ was adjusted to $9.5-10$ by addition of ammonia solution ( $29 \mathrm{wt} \%)$. After the titration, the suspension was stirred at ambient condition for $4 \mathrm{~h}$, and then hydrothermally treated at $180 \pm 5{ }^{\circ} \mathrm{C}$ for 8-12h. Subsequently, the precipitates were vacuum filtered, washed four times using deionized water, and finally freeze-dried at $-50{ }^{\circ} \mathrm{C}$ for $48 \mathrm{~h}$.

Phosphate bioglass was prepared by a melt method using $17 \mathrm{~mol} \% \mathrm{CaCO}_{3}, 15 \mathrm{~mol} \% \mathrm{SiO}_{2}, 6 \mathrm{~mol} \%$ 
MgO, 5 mol\% ZnO, 22.5 mol\% $\mathrm{NH}_{4} \mathrm{H}_{2} \mathrm{PO}_{4}$, and 12 mol\% $\mathrm{Na}_{2} \mathrm{CO}_{3}$ (AR, Sinopharm Chemical Reagent Co., Ltd., China). The bioglass was then grinded by wet ball milling with alcohol for 1-2d and dried in an oven at $50{ }^{\circ} \mathrm{C}$ for $8-12 \mathrm{~h}$ for use.

Preparation of slurry and HA scaffolds. The aqueous suspensions for HA scaffolds were prepared by dispersing HA powder and bioglass powders (bioglass: HA=0-0.3: 1 ) in solution, in which contained $0.2 \mathrm{wt} \%$ dispersant (sodium polyacrylate, $\mathrm{M}=\sim 3^{*} 10^{7}$, Sinopharm Chemical Reagent Co., Ltd), 1 wt\% binder (Tylose, $\mathrm{H}=300$, Gmbh\&Co. KG), 50wt\% coagulant aid (Dioxane, $\mathrm{C}_{4} \mathrm{H}_{8} \mathrm{O}_{2}$ Sinopharm Chemical Reagent Co., Ltd) and DI water. After dispersion completely, the slurry was poured into a Teflon mold of $\sim 10 \mathrm{~mm}$ in diameter \& $20 \mathrm{~mm}$ in thickness, and placed on a cold copper substrate whose temperature controlled using a cryostat tank. The cooling rate ranged from $0.2 \sim 1{ }^{\circ} \mathrm{C} / \mathrm{min}$. Frozen samples were put into a freeze-dryer at $-55 \pm 3{ }^{\circ} \mathrm{C}$ for $48 \mathrm{~h}$ before sintering at $950^{\circ} \mathrm{C}, 1000^{\circ} \mathrm{C}, 1050^{\circ} \mathrm{C}$ by a heating rate of $5 \sim 8{ }^{\circ} \mathrm{C} / \mathrm{min}$ in an air furnace.

Characterization of the products. The products were characterized using X-ray powder diffraction (XRD) (D/MAX-RB, RIGAKU, Japan) and Fourier-transform infrared spectroscopy (FTIR, Nicolet iS10, Thermo Nicolet, USA). Morphology and microstructure were observed using a scanning electron microscope (SEM, JSM-5610LV, JEOL, Japan). The porosity of the sintered porous samples was measured with Archimedes principle, and its compressive strength was conducted on a materials testing machine. Four specimens were prepared for each condition.

\section{Results and Discussion}

Fig. 1 shows the XRD patterns of the pure HA scaffolds and HA scaffolds with 20 wt\% bioglass sintered at various temperatures. No phase change was found for the pure HA scaffolds prepared at $1050{ }^{\circ} \mathrm{C}$. For the HA scaffolds with bioglass, new phases, assigned as $\beta-\mathrm{Ca}_{3}\left(\mathrm{PO}_{4}\right)_{2}(\mathrm{PDF}$, No.09-169) and $\mathrm{Ca}_{2} \mathrm{P}_{2} \mathrm{O}_{7}$ (PDF, No.09-346), appeared in the samples, which indicated that HA has been begun to decompose and form HA/TCP biphase composition, but containing few $\mathrm{Ca}_{2} \mathrm{P}_{2} \mathrm{O}_{7}$ phase in the products.

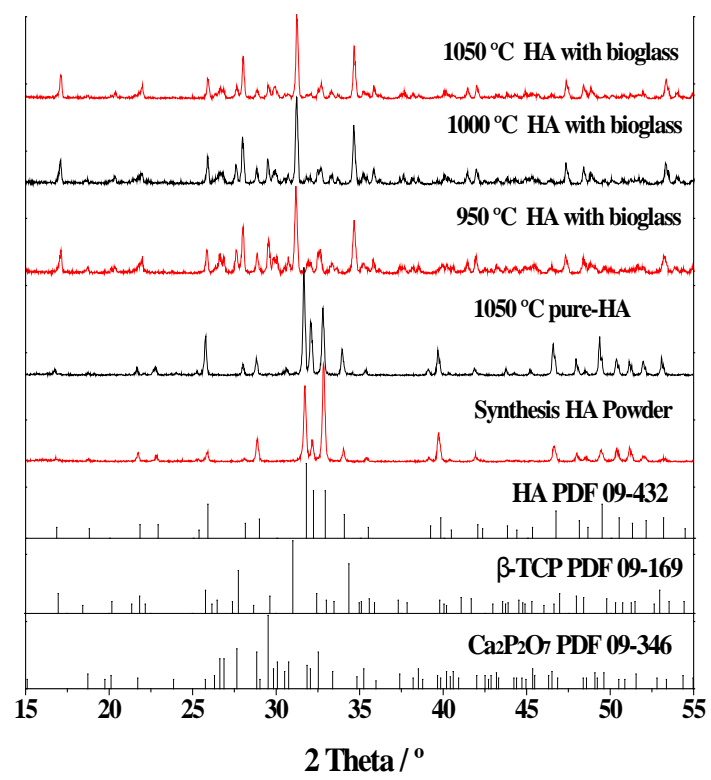

Fig.1 the XRD of synthesis HA, pure HA scaffolds and the HA scaffolds with $20 \mathrm{wt} \%$ bioglass

Fig. 2 shows the FTIR spectra of the products prepared at $950-1050^{\circ} \mathrm{C}$. For the pure HA scaffolds, the characteristic bands for phosphate group at about 1092, 1034, 605 and $565 \mathrm{~cm}^{-1}$, and bands for hydroxyl group at 3570 and $638 \mathrm{~cm}^{-1}$ were clearly visible in the spectra. Whereas, for the scaffolds with glass, characteristic bands for pyrophosphate at 1208, 946, $746 \mathrm{~cm}^{-1}$ appeared in the spectra and were similar in each. Thus, few $\mathrm{Ca}_{2} \mathrm{P}_{2} \mathrm{O}_{7}$ was demonstrated in the scaffolds when the samples were sintered with the bioglass binder, which was coincident with the previous study [11]. 


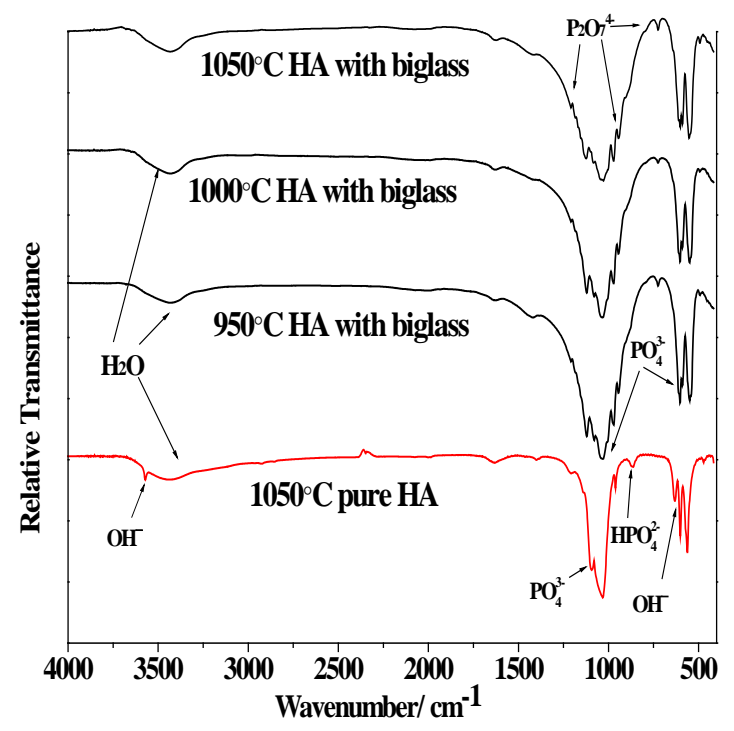

Fig. 2 the FTIR spectra of the different products prepared at different sintering temperature

Synthetic HA has been proved to decompose at $>900{ }^{\circ} \mathrm{C}$ by the following reaction $[12,13]$ :

$\mathrm{Ca}_{10}\left(\mathrm{PO}_{4}\right)_{6}(\mathrm{OH})_{2} \rightarrow 2 \mathrm{Ca}_{3}\left(\mathrm{PO}_{4}\right)_{2}+\mathrm{Ca}_{4} \mathrm{P}_{2} \mathrm{O}_{9}+\mathrm{H}_{2} \mathrm{O}(1)$

As shown in Fig.1, a strong XRD peak appeared at about $2 \theta=31.1^{\circ}$, between that of HA $(2 \theta=$ $\left.31.77^{\circ}\right)$ and $\beta-\mathrm{Ca}_{3}\left(\mathrm{PO}_{4}\right)_{2}\left(2 \theta=31.02^{\circ}\right)$. According to other peaks, $\beta-\mathrm{Ca}_{3}\left(\mathrm{PO}_{4}\right)_{2}$ was the main phase for the scaffolds prepared with phosphate glass after sintering.

Phosphate glass contains amount of $\mathrm{P}_{2} \mathrm{O}_{5}$, as an oxygen-phosphorus tetrahedron $\left[\mathrm{PO}_{4}\right]$ in glass network, which could react immediately with $\mathrm{Ca}_{4} \mathrm{P}_{2} \mathrm{O}_{9}$ to become $\mathrm{Ca}_{3}\left(\mathrm{PO}_{4}\right)_{2}$ or $\mathrm{Ca}_{2} \mathrm{P}_{2} \mathrm{O}_{7}$ by the following reactions:

$$
\begin{aligned}
& 3 \mathrm{Ca}_{4} \mathrm{P}_{2} \mathrm{O}_{9}+2 \mathrm{P}_{2} \mathrm{O}_{5} \rightarrow 2 \mathrm{Ca}_{3}\left(\mathrm{PO}_{4}\right)_{2}+3 \mathrm{Ca}_{2} \mathrm{P}_{2} \mathrm{O}_{7} \\
& 3 \mathrm{Ca}_{4} \mathrm{P}_{2} \mathrm{O}_{9}+\mathrm{P}_{2} \mathrm{O}_{5} \rightarrow 4 \mathrm{Ca}_{3}\left(\mathrm{PO}_{4}\right)_{2}
\end{aligned}
$$

In addition, when the sintering temperature was approaching or more than the melt point of the glass, the diffusion of liquid phase melted would promote the phase transformation of HA, as indicated in the reaction (1).

Fig.3 shows the shrinkage rate, porosity and compressive strength of the scaffolds sintered with different content of bioglass at various sintering temperatures. For the content of the bioglass being $<10 \mathrm{wt} \%$, all the scaffolds were broken into pieces under a small press. When its content was $>20 \%$, the samples were found to be seriously deformed, with low porosity, and hardly maintaining the desired shape and porosity. Thus, 10wt\%-20wt\% bioglass would be appropriate to prepare HA scaffolds, which had a low shrinkage rate of 3-13\%, a high porosity of $74-78 \%$ and compressive strengths of 0.1-0.6 MPa. Besides, those scaffolds could maintain their desire shape. The optimum content of the bioglass was $20 \mathrm{wt} \%$, contributing a HA scaffolds with a shrinkage rate about $8 \%$, a porosity of $74 \%$ and compressive strengths of $0.6 \mathrm{MPa}$.
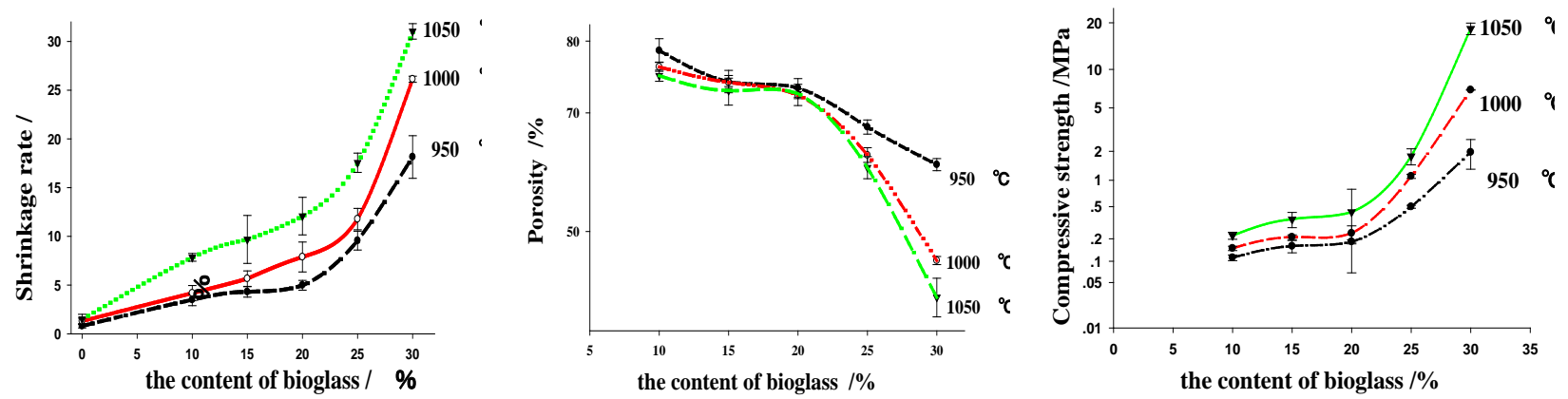

Fig.3 Effect of the content of glass on shrinkage rate, porosity and compressive strength at different sintering temperature 
Fig.4 shows the SEM micrographs of the HA scaffolds prepared with the phosphate glass binder. Their pore size prepared by freezing-dry casting was about $20 \sim 50 \mu \mathrm{m}$. No aggregates for both bioglass and HA particles were found. The bioglass was uniformly dispersed in the mixture and coated on the surface of the HA particles, indicating that the prepared bioglass binder could be used as a binder to prepare the HA scaffold at a low sintering temperature.
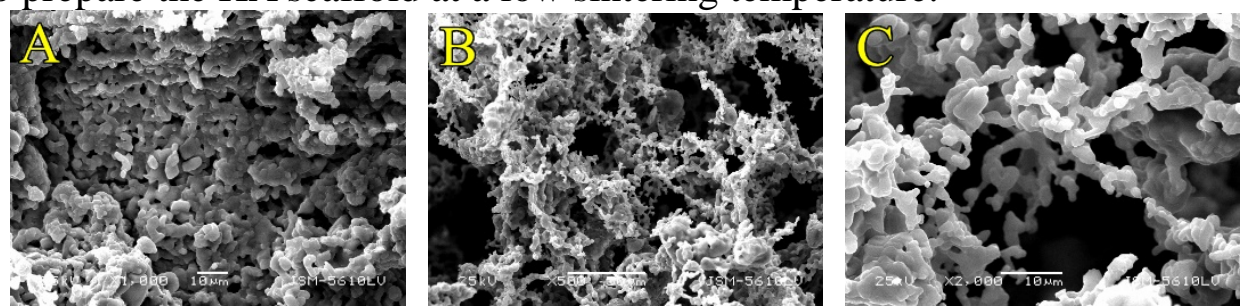

Fig. 4 the morphology of HA scaffold with $15 w t \%$ bioglass (A), 20wt\% bioglass (B, C)

\section{Summary}

The phosphate bioglass as a binder could successfully reduce the sintering temperature of HA scaffolds formed by freezing-dry casting. Such bioglass also accelerated the phase transformation of $\mathrm{HA}$ to $\beta-\mathrm{Ca}_{3}\left(\mathrm{PO}_{4}\right)_{2}$ and $\mathrm{Ca}_{4} \mathrm{P}_{2} \mathrm{O}_{9}$. The reaction between the phosphate bioglass and $\mathrm{Ca}_{4} \mathrm{P}_{2} \mathrm{O}_{9}$ formed by the phase transformation $\mathrm{HA}$ easily promote the formation of $\beta-\mathrm{Ca}_{3}\left(\mathrm{PO}_{4}\right)_{2}$, leading to a HA/TCP biphasic composition in the scaffold. The optimum content of the phosphate glass was about $20 \mathrm{wt} \%$ for preparation of the scaffolds with a high porosity and compressive strengths.

\section{Acknowledgement}

This work was supported by National Nature Science Foundation of China (No.51372182) and the Fundamental Research Funds for the Central Universities (No. 2011-IV-133).

\section{References}

[1] Hench, L.L., D.E. Day, W. Holand, Int. J. Appl. Glass Science, 1(2010), p. 104-117.

[2] Gerhardt, L.C. and A.R. Boccaccini,. Materials,. 3(2010), p. 3867-3910.

[3] Nagase, M., Y. Abe, M. Chigira, Biomaterials, 13(1992), p. 172-5.

[4] Uo, M., M. Mizuno, Y. Kuboki, Biomaterials, 19(1998), p. 2277-84.

[5] Cai, S., W.J. Zhang, G.H. Xu, J. Non-Crystal. Solids, 355(2009), p. 273-279.

[6] Arcis, R.W., A. Lopez-Macipe, M. Toledano,. Dent. Mater.. 18(2002), p. 49-57.

[7] Fu, Q., M.N. Rahaman, F. Dogan, J. Biomed. Mater. Res. Part B, 86B,1(2008), p. 125-135.

[8] Fu, Q., M.N. Rahaman, F. Dogan, J. Biomed. Mater. Res. Part B, 86B, 2(2008), p.514-522.

[9] Monmaturapoj, N., W. Soodsawang and W. Thepsuwan, J. Porous. Mater., 19(2012),p.441-447.

[10] Xin-yu, W., H. Ying-chao, L. Shi-pu, J Func Mater, 2(2003), p. 232-233.

[11] MA Li, ZHOU Ke-chao, LI Zhi-you, The Chine J Nonferrous Metals. 18(2008), p. 1885-1892.

[12] Y.F. Hu and X.G. Miao: Ceram. Int.. 30(2004), p. 1787-1791

[13] J.D. Santos, J.C. Knowles, R.L. Reis: Biomaterials 15(1994), p. 5-10 